\title{
Designing a Musical Playground in the Kindergarten
}

\author{
Cristina Core ${ }^{1}$, Andrea Conci ${ }^{1}$, Antonella De Angeli ${ }^{1,2}$, Raul Masu $^{1}$, Fabio Morreale ${ }^{3}$ \\ ${ }^{1}$ University of Trento, \\ Via Sommarive, 9 I-38123, \\ Trento - Italy \\ \{cristina.core, andrea.conci.1, \\ raul.masu\}@unitn.it \\ ${ }^{2}$ University of Lincoln \\ Brayford Pool, LN6 7TS, \\ Lincoln - United Kingdom \\ adeangeli@lincoln.ac.uk \\ ${ }^{3}$ Queen Mary University of London, \\ Mile End Road, E1 4NS \\ London - United Kingdom \\ f.morreale@qmul.ac.uk
}

\begin{abstract}
This paper investigates the involvement of preschoolers in the late stages of the design of Child Orchestra, a musical interactive playground for the kindergarten. The study presents a retrospective analysis of the design of Child Orchestra. The system was iteratively prototyped and developed following UCD methods and a design in use approach in a kindergarten over seven months. Two groups of children $(\mathrm{N}=27)$ participated in design and evaluation, a group of threeyear-olds and a group of four-year-olds. Both groups used Child Orchestra. To evaluate the system, we integrated the analysis of children's drawings with field observations and interviews with teachers. The design in use approach proved to be successful in eliciting preschoolers' needs.
\end{abstract}

Design in use. Preschoolers. Child-Computer Interaction. Interaction Design. Music.

\section{INTRODUCTION}

While still relatively young, the Child-Computer Interaction $(\mathrm{CCl})$ community has bloomed quickly. Its major contribution to $\mathrm{HCl}$ research is the identification of the major challenges in technology design for children (Bruckman, Bandlow, and Forte, 2003; Markopoulos and Bekker, 2003; Taruskin, 2009). The first identified challenge concerns the complexity of understanding children, as they have different preferences and skills depending on their age and their intra-individual variability is substantial among same age groups. The second challenge concerns the complexity of involving children in the design process (Landoni et al., 2016). While the benefit of children's contributions in the early stages of the design and in the initial evaluation phase is widely established (Guha et al., 2005; Kelly et al., 2006), the issue of their involvement in later stages needs further critical reflection (Druin, 2002).

Starting from the early elaboration on Cooperative Inquiry (Druin, 1999) and on the Informant Balanced Facilitated (IBF) design model (Read et al., 2002), numerous studies demonstrated the value of designing in intergenerational teams including children (Large et al., 2006; Xu et al., 2009). Yet, with only a few exceptions (Mansor, De Angeli, and De Bruijn, 2008, 2009), there is still a noticeable gap in the elaboration of methods to engage preschool children in technology design (Walsh, Foss, and Druin, 2013). This paper explores the involvement of preschool children in later stages of the design process by reflecting on the design of Child Orchestra, an interactive playground for music active listening. Music helps the cognitive, emotional and social development of children and plays a crucial role in increasing concentration, promoting fantasy play, self-regulating emotions, calming down and expressing joy (Saarikallio, 2009). When making music together, children tend to develop their identity and individual abilities inside a group (Kokotsaki and Hallam, 2007). Music classes are rarely offered by kindergartens across Europe and they rely on specialist knowledge from teachers, which often lacks (Rodríguez-Quiles y García and Dogani, 2011). Novel pedagogical interventions supported by technology may help addressing the issue (Camurri, Canepa, and Volpe, 2007).

In the remainder of the paper, we review related work on involving preschoolers in interaction design and outline the theory that informed the project, the Music Learning theory by Gordon. Thereafter, the paper describes the design project, showing the evolution from the ideation to the final implementation of the interfaces and the interaction paradigm in a kindergarten, which we discuss as a case of design in use following research on infrastructuring and participatory design (Dittrich, Eriksén, and Hansson, 2002). We conclude by discussing the results and presenting the implications and limitations of the study. 


\section{ENGAGING YOUNG CHILDREN IN DESIGN}

The relation among roles children can play during design can be depicted as an onion-shaped space (Druin, 2002). The inner circle represents children as users, with no involvement at all in design. Their role changes in the outer circles, where children are also involved as testers or informants during the design process. The outmost layer, children as designers, presumes the incorporation of children in the design team as a peer, capable of negotiating with adults. Consequently, when children play the designer role, the project is often referred to as a participatory design, although recent research has shown the level of participation in $\mathrm{CCl}$ projects to be limited (livari, Kinnula, and Kuure, 2015; Molin-Juustila et al., 2015).

Several characteristics make preschoolers complex design partners. According to Piaget (Piaget, 1951), early childhood fits in the preoperational phase of development (2-7 years of age). During this period children gradually improve their physical, cognitive and interpersonal skills. Despite the continuous progress towards maturity, cognition in early childhood is unique. Distinctive features are 'egocentrism' (i.e., the inability to understand a situation from somebody else's point of view) and 'centration' (i.e., the tendency to concentrate on a single aspect of a situation, ignoring the others).

Research on design for preschool children mainly involved them as testers and relied on adults to creatively re-interpret their behaviour (Mansor, De Angeli, and De Bruijn, 2008). Drawing was used to elevate the level of agency up to the role of informant in the different design stages of ideation, formative evaluation and summative evaluation. Guha et al. (2004) used drawing to inform the ideation stage. Drawing helped to engage children aged between 4 and 6 years in field observations and as a basis for brainstorming ideas. Nicol and Hornecker (2012) employed drawing to perform formative evaluations instead. They evaluated a set of early prototypes of touch screen and tabletop interfaces for a museum application by collecting drawings from children aged between 5 and 12 years, and adults. The approach proved particularly useful to facilitate discussion during interviews with children.

Drawings also allow for summative evaluations. For example, Sylla et al. (2011) analysed drawings to evaluate a graphical and tangible interface promoting oral hygiene awareness to 4- and 5-year-olds. The drawings mainly captured the central elements of the experience. This was consistent with research on children's artistic expressions, which demonstrated how they tended to avoid drawing elements that did not interest them (Chiasson and Gutwin, 2005; Xu et al., 2009).

\section{MUSIC}

A number of studies have investigated the methods for supporting music learning at young age (Gordon, 2003; Jaques-Dalcroze, 1921; Thresher, 1964). The
Music Learning Theory (Gordon, 2003) provides an integrated and operational explanation of how children learn music. It stresses the importance of learning music by hearing as opposed to the methods that concentrate on musical notations. In particular, Gordon (2003) proposes active listening as a method to enhance listening skills: instead of just sitting, children actively move while listening to music. Physical interaction and movement engage children's attention and memory, and thus, help to enhance listening skills (Sims, 1986).

To maximise the effect of active listening, children should be exposed to a variety of music that has to be coherent $^{1}$ (Gordon, 2003). An orchestra performs music with a certain polyphonic complexity. Polyphony literally means 'many' (poli) 'voices' (phoné) (Taruskin, 2009). The theories and knowledge discussed above provided the theoretical foundation for the development of Child Orchestra. In particular, we integrated the concepts of active listening and musical variability in an interactive system capable of generating polyphonic music that can be manipulated in real time.

\subsection{Music and Technology}

Recent research tried to use ICT technology to enhance traditional musical instruments and design new interactive systems for children. Nijs and Leman (2014) developed the 'Music Paint Machine', a system that helped children aged 5-7 to play the clarinet. The system captured body movements while playing a clarinet and translated those movements into a digital drawing projected on a wall. The system mapped torso, feet movements and hand articulation on pitch and volume parameters (Nijs et al., 2012). Notably, the system added a visual dimension to the music and allowed for monitoring children's performance.

The 'Continuator' facilitated piano learning by automatically engaging in musical dialogues with a child performing on a keyboard (Pachet, 2003). The system, which was designed for children aged 3-5, takes the music performed on the keyboard as an input and plays back coherent excerpts that mirrors the child behaviour (Pachet, 2003). The system could capture and hold children's attention during the musical activities (Antle, Droumeva, and Corness, 2008). Hiding the technological infrastructure also appeared to enhance user experience and increase engagement (Druin, 1999).

Several systems were built to allow children manipulate musical tracks through body movements. 'You're the Conductor' was a system aimed at the 4 to 11 year old children. A child played the conductor by controlling volume and tempo with an augmented baton (Lee, Nakra, and Borchers, 2004). The child controlled pre-recorded music by moving his arms:

\footnotetext{
1 Musical coherence refers to the proper use of chords, scales, and rhythms applied in a given set of compositional rules.
} 
the faster they move the faster the music; the wider their arm movements the louder the music.

Antle, Droumeva, and Corness (2008) designed another system exploiting embodied cognition for teaching music to 7 - to 10-year-olds. Body movements were captured by a tracking system and mapped onto a percussive sound output. Tempo was mapped on the speed of movement, volume on the intensity of activity, and pitch on the proximity among children. However, the system did not control harmonic and melodic features of music.

Musical mobile and tablet apps and games have also been developed (Rajan, 2014). Hein differentiated games with educational purpose (e.g., teaching the player to read and write notes; rhythm-oriented games such as 'Guitar Hero', where the player follows visual cues to play back a song in time) and 'music toys', which allowed children to improvise music (Hein, 2014).

\section{DESIGNING CHILD ORCHESTRA}

The design of Child Orchestra was inspired by the work discussed in this section. In particular, considerable attention was paid to exploring new interaction paradigms that could be seamless and intuitive for groups of children. In addition to previous work, Child Orchestra allowed participants (both children and teachers) to have a direct control on a single voice of the music, making their individual contribution to the polyphony identifiable. Furthermore, the system guaranteed a musical coherence, which is crucial for exposing preschoolers to a valid musical stimulus.

The design and development of Child Orchestra involved different actors and UCD methods. This process contains four main phases: inspiration, acceptability analysis, conceptual design, and design in use. The inspiration was initiated during the public exhibitions of the Music Room, a musical installation designed to allow naïve listeners to make music while moving in a space (Morreale et al., 2014). Even though the installation was designed for an adult population, children of different ages engaged with it, chasing their partner, twisting, and rolling their body. The music followed their movements, and although we were not sure whether the children associated their movements to the music, it was evident that they enjoyed it. The acceptability of a Music Playground and the practical constraints to use it in a kindergarten were evaluated in two focus groups with parents $(\mathrm{N}=12)$ and teachers $(\mathrm{N}=10)$. Low cost, robustness and ease of use were the main constraints that emerged. The conceptual design phase consisted in workshops with teachers and prototyping activities.

\subsection{Workshops}

The aim of the workshops was to elaborate the conceptual design of the music playground. Specifically, we wanted to define the learning objectives of the system, to understand which kind of musical stimuli were better suited for preschool children (music style), and envision possible interaction metaphors to interface children and music (interaction style). The workshops involved an interaction designer, a composer, five music teachers and an artist in residence. Each workshop lasted 1.5 hours including brainstorming and structured activities facilitated by different probes (images and videos, paper-based scenarios).

The teachers elaborated different ideas on how Child Orchestra could be used in their teaching practices. The most innovative aspect was the possibility of augmenting active listening with the direct manipulation of polyphonic music. They envisioned an environment which could help children not only to recognise variations in different structural music parameters, but also to independently agree on adopting a classical-like music genre, although they suggested to create a synthetic sound to avoid biasing children behaviour with the association to real life instruments.

The insights gathered during the workshops were elaborated by the design team in two storyboards representing possible directions for the design. They were drawn in cartoon style (Figure 1) by an artist and discussed with two music teachers experienced in preschool education, who volunteered their time and knowledge.

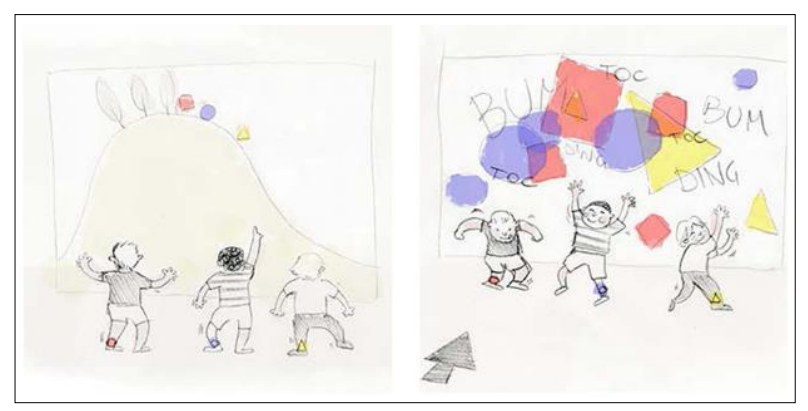

Figure 1: Initial storyboards.

This feedback informed the development of a prototype $^{2}$ presenting two scenarios with a coherent musical track. One scenario recreated a scene of the Nabucco by Giuseppe Verdi. Each child played the role of a character wearing costumes, masks and using objects related to it. The stage was covered by a large carpet of different colours associated to a prerecorded music clip. Children had to listen carefully to the opera: when their turn came they moved to the correct area of the carpet and triggered the voice of their character by moving their arms. The second scenario described a situation in which children selected their favourite costume, mask, and other objects and built their own Musical Tale accordingly. This scenario exploited automatic music composition to give children control on low level parameters of the composition. For example, they could control the

2 https://youtu.be/m-UIKx9F90E 
speed by moving to a specific area or the volume of their instrument by moving their arms.

The scenarios were discussed in a new workshop with teachers. Overall, they preferred the second scenario as it allowed a more direct control on the music, although they felt the need for a clearer structure of the activity. The main outcome of this design section was a three-staged educational format for the Child Orchestra. The first phase, acculturation, was meant to help the children to distinguish a number of musical parameters, specifically speed $^{3}$, articulation and volume. They had to move spontaneously according to the variations of the music, which was controlled by the teacher. In the second phase, sound manipulation, children directly controlled the musical parameters by means of specific movements. In particular, speed was controlled by movements, and articulation by proximity. The control of volume was given to a child that played the role of the conductor. In the third phase, narration, storytelling and fantasy play were introduced. Children dressed up and invented their own stories while making music.

\subsection{Wizard of $\mathrm{OZ}$}

The three-staged educational format was pilot-tested through a new iteration of the prototyping phase, which was developed as a video using a Wizard-ofOZ method with the help of a tutor. Three children (5 to 6 years old, two females and one male) were invited to act for the video (Figure 2).

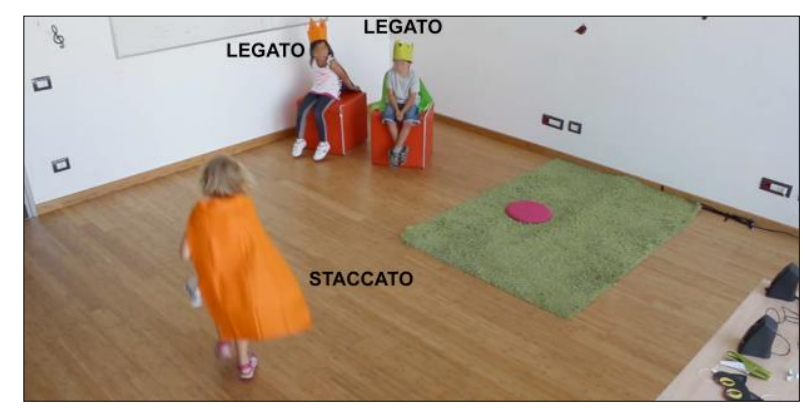

Figure 2: Hi-Fidelity prototype.

The children were accompanied by one parent who signed a consent form allowing us to use the recordings for research purposes. Involving the children in this phase was fundamental as a preliminary evaluation of their experience allowed us to identify specific behavioural challenges. For example, a child was reluctant to follow the instructions of the tutor and remained for most of the time at the margins of the interaction space, paying little attention to the tasks. However, during the narration phase he was excited to play the part of the king and showed a keen interest in the activity. In general, costumes were perceived positively even if they were sometimes intrusive. In particular, masks

3 References to speed are to the rhythmic density of the melodies rather than the general tempo (BPM). were discarded, as the holes for the eyes did not perfectly fit the child's face. This episode taught us another important lesson: less invasive objects (e.g. magic wands, crowns, swords, and capes) are preferable, as they do not hinder children's movements.

Table 1: Requirements emerged during the conceptual design phase.

\begin{tabular}{|c|c|}
\hline \multirow{4}{*}{$\begin{array}{l}\text { Learning } \\
\text { Outcomes }\end{array}$} & Promote active listening. \\
\hline & $\begin{array}{l}\text { Distinguish variations in speed, } \\
\text { volume, and articulation. }\end{array}$ \\
\hline & Recognize the voices of a polyphony. \\
\hline & Encourage music making. \\
\hline \multirow{4}{*}{ Music Style } & Classical music style. \\
\hline & Coherence of the polyphony. \\
\hline & $\begin{array}{l}\text { The timbre should not resemble that of } \\
\text { any existing instruments. }\end{array}$ \\
\hline & Present a wide range of varied music. \\
\hline \multirow{6}{*}{$\begin{array}{l}\text { Interaction } \\
\text { requirements }\end{array}$} & $\begin{array}{l}\text { Children controlled low-level } \\
\text { parameters. }\end{array}$ \\
\hline & $\begin{array}{l}\text { Each child autonomously controlled a } \\
\text { voice. }\end{array}$ \\
\hline & Promote social interaction. \\
\hline & Technology should be transparent. \\
\hline & Provide tangible objects \\
\hline & $\begin{array}{l}\text { Give a small set of clear rules to avoid } \\
\text { distractions. }\end{array}$ \\
\hline
\end{tabular}

The videos were particularly effective in communicating the idea of the Child Orchestra. Ultimately, a music teacher decided to use it in practice in a kindergarten and participate with us in the actual development. A summary of the requirements elicited throughout the conceptual design phase is reported in Table 1.

\section{TECHNOLOGICAL INFRASTRUCTURE}

Once the prototyping process was complete, we built a first version of the technological architecture to experiment with in the kindergarten. The system consisted of two main modules: a composer and two controllers. The composer was an extension of Robin (Morreale, Masu, and De Angeli, 2013; Morreale and De Angeli, 2016), a rule-based algorithmic system to manipulate volume, articulation and speed (defined as the rhythmic density of the melodies rather than the general tempo BPM). The algorithmic composer implemented several music modes in order to expose children to a larger variety of music stimuli and obtain a good longevity of the system. The algorithm is composed of three modules that separately deal with: (i) harmonic progression, which follows traditional harmonic rules (Piston, 1948; Schoenberg, 1978), implemented with a first order Markov chain; (ii) rhythm, which is composed of four modules that computed the rhythm of each melody; and (iii) 
melody, which fills all the four rhythms with notes coherent to the current chord. Further details about the composer are provided by Masu et al. (2017).

The algorithmic solution allowed to generate multiple melodic voices in real-time, so that each child could control their melodic voice without reciprocal interference. To restrain the musical outputs according to melodic and harmonic rules the algorithm managed counterpoint (Molin-Juustila et al., 2015). The music recalled the timbre of an organ but with extended capabilities in terms of controlling the attack of the notes to emphasise differences in articulation.

The controllers were developed as interfaces to be used by teachers and children to control the music generated by the algorithm. This distinction reflected the different requirements of the three-staged learning format. During the acculturation phase, the music was controlled by the teacher using a remote controller; during the other two stages, each child controlled by body gestures through a tracking system. Taking into consideration the limited familiarity of teachers with technology and the cost, the remote controller was implemented as a smartphone. The first prototype of the tracking system adopted an infrared-based (IR) solution: using computer vision techniques, a low-cost IR camera mounted on the ceiling tracked objects augmented with IR LEDs. This solution proved wrong in practice, as the children's fast movements generated several failures due to visual occlusions. Therefore a new tracking system was developed, using objects with embedded motion sensors such as accelerometers. This solution ensured continuity of signal and a better control, and appealed to the natural preference of children.

\section{DESIGN IN USE}

The conceptual design of the Child Orchestra was used in the kindergarten of Cavedine and iteratively modified in practice over a period of seven months, from November 2015 to May 2016. The process was supported by reflection-in-action (Schon and DeSanctis, 1986), which allowed us to incrementally refine the Child Orchestra while in use. To describe this phase we adopt Dittrich e al. (2002) definition of 'design in use' as the process able to 'capture practices of interpretation, appropriation, assembly, tailoring and further development of computer support in what is normally regarded as deployment or use'. The analysis reported is based on the triangulation of different data sources, including field observations, drawing analysis, an in-depth diary filled in by the music teachers after each session and 3 semistructured interviews with the teachers who supervised the activity.

\subsection{Participants}

A total of 27 children (13 males, 14 females) participated in the design process. They were divided in two classes based on age: one class was composed of 15 children aged 3 (4 males, 11 females); the other one was composed of 12 children aged 4 (9 males, 3 females). This criteria was particularly relevant because of young children's indevelopment skills such as drawing and writing skills. Ethical approval was obtained by all parents before the study began. However, only half of them granted us the right to use videos.

\subsection{Context}

The kindergarten of Cavedine was a small-sized one in the rural area north of Trento (Italy) gathering 42 children at the time of the study. Around $14 \%$ of them came from a foreign family but all of them were born in Italy and were proficient in Italian. The children attended the school 7 hours per day from Monday to Friday. The Child Orchestra was set up in a large room ( $7 \times 7$ metres). The room was unfurnished with a large blue carpet, two loudspeakers, and a control desk (Figure 3).

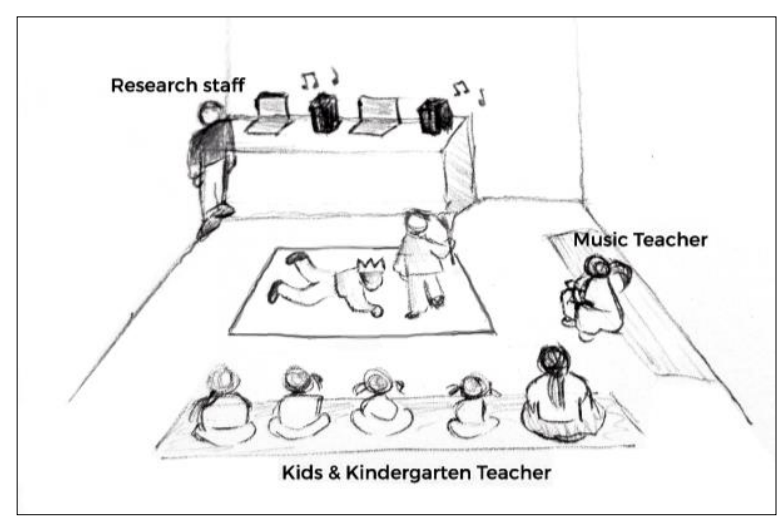

Figure 3: Setup of the room in which the activities with Child Orchestra took place.

\subsection{Procedure}

The design activities were part of the educational curriculum of the Cavedine kindergarten and were offered to the children free of charge. They were structured according to the three-staged educational format (acculturation, manipulation and narration) defined in the conceptual design. Each stage included a set of 30-minutes workshops held by the music teacher in collaboration with one kindergarten staff. The music teacher, together with a music researcher, mediated the children's needs by reporting to the research staff the behaviours she observed during each session and by participating directly to the decision making process determining both the didactics and the interaction paradigm. This double role of the music teacher helped us to adapt the interactive paradigms and the interfaces according the activities of the music session. At the end of each session, children were invited to create a drawing inspired by the workshop. Then, the kindergarten teacher asked each child to explain the meaning of the drawing and noted down the explanation. At the end of the design process the teachers were interviewed. 
Three researchers with expertise in Human-Computer Interaction, with one of them having a strong musical background, analysed the 209 drawings collected during the study. The thematic analysis was performed in two main phases. During the first phase the researchers familiarized with the data, defined the codes and their definitions. After multiple iterations and discussions, the researchers identified five main themes: sociability, happiness, music, movements, and tools. Sociability identified the presence of human figures in the drawing or/and a clear statement of the presence of people in the teacher's note. People that were not related to the experimental setting (e.g. 'my uncle') were omitted. Happiness theme identified the presence of elements referring to children's experience in the drawing or in the teacher's note. For example a representation of him/herself with an happy face was coded as positive. The music theme established the presence of music related elements in the drawing or in the teacher's note (e.g. the drawing of musical notes or a written description of the music in the note). The movements theme indicated the representation of movement and/or the description of physical movements in the teacher's note. The coding distinguished between the movement correlated with music and an unrelated movement. In the end, the tools theme determined the representation or description of tools used in the experimental setting. The coding distinguished between the active tools (e.g. sceptre), passive tools (e.g. carpet) and other tools (e.g. technical equipment).

Table 2: Example of one coding of one researcher.

\begin{tabular}{l|l|l} 
& Scores of Fig. 4 & Scores of Fig. 5 \\
\hline Sociability & Human figures & Author \\
\hline Happiness & Present/happy & $\begin{array}{l}\text { Not } \\
\text { present/undefined }\end{array}$ \\
\hline Music & $\begin{array}{l}\text { Depicted and } \\
\text { described }\end{array}$ & $\begin{array}{l}\text { Depicted and } \\
\text { described }\end{array}$ \\
\hline Movement & $\begin{array}{l}\text { Present and } \\
\text { related to music }\end{array}$ & $\begin{array}{l}\text { Present and } \\
\text { related to music }\end{array}$ \\
\hline Tools & $\begin{array}{l}\text { Carpet and } \\
\text { other tools }\end{array}$ & Not present
\end{tabular}

In Table 2 we report one example of coding of one researcher related to Figure 4 and Figure 5. During the second phase, the coding actvity was performed independently by each researcher using the codes and definitions emerged in the previous phase. Results coming from the three coders were compared and tested to assess the inter-coder reliability by using the Cronbach's alpha test $(\mathrm{N}=3)$. The values of Cronbach's alpha were greater than 0.90 for all the themes, thus highlighting that the coding activities were highly reliable. The amalgamate result of all coders was computed as the most frequent value among the coder's ratings. When all the codes differed we picked the median value.

\subsection{Phase I: acculturation}

The acculturation phase was divided into three subphases: a) observation of the children's spontaneous behaviour in a free play condition; b) definition of a set of exercises to facilitate the recognition of systematic variations of each individual parameter; and $\mathrm{c}$ ) introduction to polyphonic music.

\subsubsection{Free Play}

During workshop 1 and 2 the children familiarized with the environment and the music. They were exposed to the combined variations of volume, speed, and articulation. The music was controlled by the teacher with the remote control and the children were invited to move freely inside the carpet following it. A polyphonic music with four voices was played and the variations occurred on all the voices at the same time. Initially, the teacher played with the children, but, as the time passed by, she suggested specific movements to keep them focussed on the music. These movements were based on the observation of children's spontaneous behaviour and mainly targeted younger children. To help the 3-year-old children to recognise the changes in the music articulation, the teacher used the carpet. When the music was staccato, the children were required to jump outside of the carpet, as opposed to jumping into the carpet for legato. Interestingly, the children, not only, reacted correctly to the changes but they also jumped following the beat of the music. To keep older children focussed on the music, the teachers divided them into small groups that were invited to play inside of the carpet in turns.

Despite the need for increased structure, it was evident that the children spontaneously reacted to the music variations. Their reaction, however, was modulated by the different parameters and their combination. All of the children instinctively performed fast movements (such as running, or spinning) when the music was fast, but their reaction to slow music was more delayed and less evident. In particular, children were more reactive to changes in speed when the articulation was staccato and the volume was low. The parameter which appeared to be easy to perceive was articulation, particularly while changing from legato to staccato. In general, children tended to react to staccato by walking in time with the music and thus displaying robotic movements. Finally, as a general observation, we realised that the music was too repetitive to fully engage children. For this reason we modified the algorithmic composer consequently.

Overall, the children enjoyed the workshops. Independent of age, their drawings mainly focussed on other children and the teacher, as well as their movements, rather than on the music. Interestingly, most of the drawings of children aged 4 displayed smiling faces. This framework matches the teachers' observation describing an engaging experience, but with little focus on the music. 


\subsubsection{Structured exercises}

The next three workshops focused respectively on articulation, speed and volume proposing three simple game-like exercises for each parameter (Table 3 and 4). Only one parameter at the time (fixed parameter) was manipulated within each exercise, whereas the other ones varied between exercises (varying parameter). The changes were consistently applied to all the four voices. To increase the music variability each exercise was associated to a different scale. A summary of the exercises and a description of the music played in each of them is reported in Table 3 and 4.

Table 3: Fixed and varying parameters in the structured sessions.

\begin{tabular}{c|c|c|c} 
& Session 3 & Session 4 & Session 5 \\
\hline $\begin{array}{c}\text { Fixed } \\
\text { Parameter }\end{array}$ & Articulation & Speed & Volume \\
\hline $\begin{array}{c}\text { Varying } \\
\text { Parameter }\end{array}$ & Speed & Articulation & Articulation
\end{tabular}

Table 4: Details of the varying parameters varying in the exercises in the structured sessions.

\begin{tabular}{l|c|c|c} 
& $\begin{array}{c}\text { Speed in } \\
\text { Session 3 }\end{array}$ & $\begin{array}{c}\text { Articulation } \\
\text { in Session 4 }\end{array}$ & $\begin{array}{c}\text { Articulation } \\
\text { in Session 5 }\end{array}$ \\
\hline Exercise 1 & Low & Legato $^{4}$ & Legato \\
\hline Exercise 2 & Medium & Staccato $^{5}$ & Legatissimo $^{\text {Leg }}$ \\
\hline Exercise 3 & High & Legatissimo $^{6}$ & Staccatissimo $^{7}$
\end{tabular}

Behavioural observations in session 3 confirmed a mediation effect between speed and articulation. Children reacted more easily to extreme variations. In particular, when the music was fast or the music was staccato, they had troubles noticing the changes. After a few trials, however, all the children reacted as expected. All exercises of session 4 (Figure 4 and 5) proved to be successful, specifically the legato condition with medium volume levels (between piano and forte). Children moved in circles while changing the speed of their movements, and were able to discriminate variations in the music. In their drawings, they described the music as slow or fast, or as "toc toc" (staccato) or "like a wave" (legato). The central element of this session was the music, which was present in all the drawings; movements were rarely depicted.

\footnotetext{
${ }^{4}$ Notes are played smoothly and connected.

5 Notes are played separated and distinct.

6 Notes are played smoothly and extremely connected.

7 Notes are played extremely separated and distinct.
}

Session 5 highlighted that variations of volume were often disregarded and children tended to move by following speed and articulation parameters. The variations of volume especially for extreme articulation values such as staccatissimo and legatissimo were less clear and the assistance of the teacher was necessary to make the children notice the changes. On the other hand the combination of low volume together with staccatissimo and high volume together with staccato seemed to be more effective. Drawings reflected this trend and showed no connection with the volume.

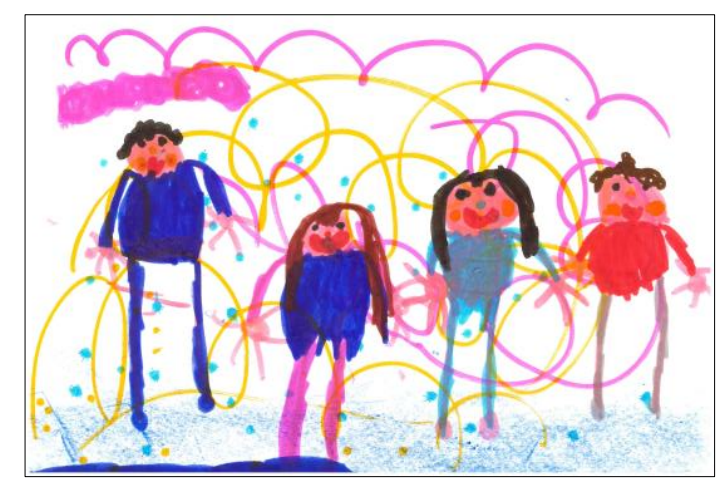

Figure 4: Example drawing of a 4 year old child (lesson 4). The teacher note reports: 'I drew myself and my friends. We play with Child

Orchestra. With the striped music we had to stay inside. With the toc toc toc music we had to stay outside.'

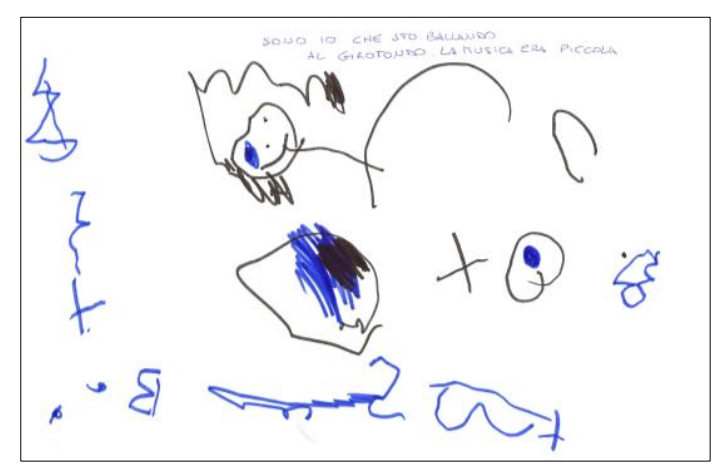

Figure 5: Example drawing of a 3 year old child (lesson 4). The teacher note reports: 'It is myself dancing in ring around. The music was little.'

At the end of the structured exercises, the children reacted with a very little latency to each parameter, when changed independently. When more than one parameter was changed at the same time, the children struggled to understand what was happening.

\subsubsection{Polyphonic Music}

Sessions 6 and 7 were conducted to help the children to recognise a polyphonic composition of two or three voices. The teacher manipulated the speed and the articulation of the different voices independently, using the remote control. The children were exposed to a specific voice and asked to react to its changes independently of the others. In this phase, the children 
were divided into subgroups (2-4 people) and experienced the system in turns.

In general, the children appeared to be capable to recognise their voice correctly, particularly as regards the highest and the lowest voices. Music and movement were the central elements of the drawings of this phase. Furthermore, it was evident that manipulating more than one parameter was difficult for the teacher and confusing for the children. Consequently, we decided to use a two-voice polyphony manipulating only speed for the following sessions.

\subsection{Phase II: manipulation}

In session 8 the children were given active control over the music. For the first time, they were told that the music would follow their movements. To make it clear, the teacher physically followed the children using the remote control according to their movements. This session was crucial to introduce the concept of active control over the music. The teacher highlighted that the system worked also thanks to her relation with the children and this let them understand that the teacher made the music go faster as they accelerated.

In session 9, the children were given two 'magical objects' (two crowns) they could use to control the music. Each child controlled an independent line. Initially, they acted solo, then in a group of four. However, as they showed some shyness when alone and groups of four were too large to create a meaningful music, the session was organized in couple shifts. The children tended to move a lot their arms, thus we planned to introduce a second object: a sceptre. Looking at the drawings, half of the 4-yearold children described clearly the relation between the music and their movements, thus showing that they were aware of controlling it. This relation was less clear for the 3-year-old children as only one third mentioned it in the drawings.

The activities performed in session 10 were designed for couples of children: one child had the crown, the other one the sceptre. The session began with a demonstration of the crown and the sceptre, then the children were asked to try the objects. The children entered the active area one at a time and the gradual activation of the individual voices was useful to help them to recognise the different musical lines in the polyphonic melody. The introduction of the sceptre was generally well accepted, and it was depicted together with the crown in most of the drawings. Moreover, they induced a couple of spontaneous fantasy play episodes during the session. At the end of each session, the music teacher asked the children to describe the music, their movement and the resulting musical changes. The children were able to remember and describe the music correctly.

\subsection{Phase III: Narration}

In session 11 and 12 the narrative elements were introduced. Elements such as animal characters they could interpret and situations where they can imagine themselves were useful to support fantasy play and thus promote their engagement (Berk, 2006). During the narration phase the children gradually reinterpreted and appropriated the plot of the stories. Stories were partially inspired by existing tales but characters and other details were chosen directly by the children. We report an example of a story. The story had a witch/wizard controlling a low voice, and a princess/prince controlling a high voice. The plot was the following:

A few puppies went lost in the forest.

(i) The groundhog was sleeping, the music has to be very slow, otherwise, the animal will get up.

(ii) The happy butterfly required to be vitalized, so they will show the way out of the forest, the music is to be very fast.

(iii) The chatty bear appears in the distance, the witch/wizard uses his power to talk to the bear and the princess/prince must not disturb. The low voice is thereby active and the high one is very slow.

(iv) It is night, the sceptre lights up the surface of a lake, the royal swan appears floating on the water. The princess/prince has to run to summon the attention of the animal. The low voice is very slow and the high one is very fast.

The accuracy of the movements of the children played a critical role in the narrative. In turn, each child played the role of the witch or wizard and the other played the role of the princess or the prince. They performed actions to help the puppies to avoid the dangers of the forest. For instance, they had to move slowly to avoid to wake up the bear, or to hurry when followed by the bear. Social interactions between the children were fostered by the stories. All the stories had the same aim: to help the children to get out of the forest. They were designed in order to promote four combinations of speed: fast-fast, fast-slow, slowfast, slow-slow. Children liked the animal character and it was easy for them to engage in fantasy play. Also the choice of the forest was appropriate because children could easily imagine this environment. In the drawings, both groups depicted the animals, the trees, and the rivers as central elements; the sceptre and the crown were less present respect to the previous session.

\section{DISCUSSIONS}

In this paper, we have described a longitudinal design case study aimed at the development of a musical playground in the kindergarten. Despite a long and rich phase of analysis supported by adults, the most 
important suggestions for the Child Orchestra derived from the enactment of the conceptual design in the kindergarten. This was the moment during which the design that was built following specific design activities was shared with the intended final users, the preschoolers, in a familiar context, the kindergarten. In this sense and by conceiving the design process as a continuous one we reflect on the involvement of such population in a late design stage (Dittrich, Eriksén, and Hansson, 2002). In this phase the children became the real actors of the project, and a more genuine participation was achieved (livari and Kinnula, 2016). While enacting the design in the context of a kindergarten we listened to the children's voice using the language they speak (Piaget, 1951), focussing on embodiment, emotions and drawings. The conceptual design was modified and improved during this phase thanks to the children's engagement.

We reflect about the design in use process. The initial phase of the process, Free Play, took place in the kindergarten and was crucial to refine the outcomes of the conceptual design. This phase was also essential to integrate the children's voice about their preferred interaction modalities both affecting the interaction with the system and expanding and tailoring the educational format. Moreover, this phase allowed us to instantiate two main requirements which emerged during the conceptual design: suggestions of movements and structured guidance were provided to the children in the form of game based exercises and the music output was constantly varied using different scales to maintain the children's attention high (Gordon, 2003). The introduction of suggestions and in general of some guidance during the activities reflects the criticalities of having preschoolers participating in a late design stage of a technological system. On one hand their involvement provides immediate feedback on the system, but on the other hand, their age-related characteristics, such as their limited attention span, need to negotiate modalities through which they can participate in the design. Furthermore, we realised that the system had to be used in small groups to allow children focusing and being more reactive to the changes in the music.

The design in use also allowed to shed more light on how to integrate a polyphonic algorithmic interactive system in the practices aimed at young children's active listening (Gordon, 2003). During the structuredexercise phase we noticed that when more than one parameter changed simultaneously the children's reactions were ambiguous. The structured approach and the focus on one parameter at a time resulted to be more effective to make the children understand the relationship between music and movement. Using extreme variation on the main parameter of the exercise helped the children to recognize changes. Surprisingly, the use of the volume parameter alone was not particularly effective, but it could be used to increase the saliency of the variations of other parameters (like low volume and low speed). The polyphony phase highlighted that children showed a more effective recognition of the voices in the music when they were in couple. When they were in bigger groups, they identified the voices with more difficulties.

Session 8 in the manipulation phase showed how the figure of the music teacher was important to enable children to understand that they were able to control the music by moving their body. This session changed the children behaviour from 'following the music' to 'actively manipulating' it, opening new important areas for musical interface design and music teaching. This phase confirmed the need of using Child Orchestra in couple. Entering one by one and gradually activating the voices resulted in a good strategy to improve the children's ability to discern voices. The spontaneous tendency of children to engage in arm movements was exploited and gave rise to the sceptre, which enabled a finer control over the music.

The narration phase showed that the use of stories fostered the active participation of the children. In particular, the use of narrative elements that were familiar to them (animals, the forest, etc.) kept them completely engaged. In this context, their focus tended to shift towards the narrative elements and the presence of the teacher revealed to be crucial to redirect the focus back to the music and the movements.

This project was a successful example of participatory design with the teachers and design in use with preschoolers. A reason for its success was that it integrated the design process within the kindergarten curriculum. During the music sessions, offered to the school as part of the project, children had the possibility to learn new skills fulfilling one of the main requirements of the participatory design ethos (Guha et al., 2005; Large et al., 2006). The teachers reported that the children were very happy to participate in the activities. Sometimes they even asked when the next activity would take place again. During the interviews the teachers pointed out that drawings had all smiling faces. According to the observations, the children were laughing and having moments of fun most of the times, as emerged in the drawings.

Children constantly influenced the design, which unfolded and evolved around their behaviour and drawings. The subjectiveness in the analysis of the drawings was limited by having a precise description of the codes to identify in the drawings, by having multiple coders, and by triangulating the data. The teachers instead acted as mediators in the design process. They modified their teaching style on the fly responding to children's behaviour and requested several adjustments to the technology to suit their evolving needs. Teachers and designers worked in a team and although each of them had specific priorities and interests, they learnt to appreciate different perspectives and collaboratively shaped the music playground.

This paper has several limitations due to the complex nature of a design in use process involving young children in a school setting. Schools are often a challenging environment to engage children in design, 
due to various reasons including established power structures between children and adults, and lack of flexibility. One could argue that children should have been given a voice earlier in the design process allowing them to shape the conceptual design, or that they should have been made more aware of their role of researchers in the project. Due to the peculiarities of preschool children and the kindergarten context, the conceptual design phase was used to negotiate technology prerequisites with key adults such as parents and teachers, and institutions. Such choice allowed us to keep a comprehensive overview over the interactive system that was keeping track of the interactivity, children's needs, and musical coherence. The late involvement of children was instead able to highlight fine-grained characteristics of the system. With this paper, we hope to stimulate further research on this stimulating topic bridging the notable gap in Child-Computer Interaction research with young children (Druin, 2002; livari, Kinnula, and Kuure, 2015; Molin-Juustila et al., 2015). Future works will also investigate on methods that can effectively capture children's experiences for this specific population.

\section{CONCLUSION}

Involving preschoolers in a design in use process helps the designers to uncover the mismatch between the interactive paradigms emerged during the conceptual design and the interactive paradigm evaluated in a naturalistic context. The interactive system should be brought in the specific context of use in a non-final developmental stage. In particular the system should be flexible in order to be adapted to the children's needs quickly and allow multiple interaction modalities.

\section{ACKNOWLEDGEMENTS}

This paper was supported by Inf@nzia DIGI.Tales 3.6, an Italian Ministry of Education project aiming to renewing and updating preschool (3-6 years old) education programmes with ICT. We are grateful to the artworks' designer Adriano Siesser, the music teacher MariaPia Molinari for her guidance throughout the study, as well as to the teachers and the children of the Kindergarden in the school of Cavedine.

\section{REFERENCES}

Antle, A.N., Droumeva, M., Corness, G. (2008) Playing with the sound maker: do embodied metaphors help children learn? In: Proceedings of the 7th International Conference on Interaction Design and Children. Chicago, Illinois, 11-13 June 2008. New York, NY, USA: ACM, 178-185.

Berk, L.E. (2006) Child Development. Boston: Pearson/Allyn and Bacon.
Bruckman, A., Bandlow, A., Forte A. (2003) HCl for kids. In: Jacko, J.A., Sears, A. (Eds.), The Human-Computer Interaction Handbook. Hillsdale, NJ, USA: L. Erlbaum Associates Inc. 428-440.

Camurri, A., Canepa, C., Volpe, G., (2007) Active Listening to a Virtual Orchestra Through an Expressive Gestural Interface: The Orchestra Explorer. In: Proceedings of the 7th International Conference on New Interfaces for Musical Expression, NIME '07. New York, NY, USA: ACM. 56-61.

Chiasson, S., Gutwin, C. (2005) Design Principles for Children's Technology (interfaces No. 7).

Dittrich, Y., Eriksén, S., Hansson, C. (2002) PD in the Wild; Evolving Practices of Design in Use. In: Participatory Design Conference. Malmö: CPRS (Computer Professionals for Social Responsibility).

Druin, A. (2002) The role of children in the design of new technology. Behaviour \& Information Technology, 21 (1), 1-25.

Druin, A. (1999) Cooperative Inquiry: Developing New Technologies for Children with Children. In: Proceedings of the SIGCHI Conference on Human Factors in Computing Systems, CHI '99. Pittsburgh, Pennsylvania, USA, 15-20 May 1999. New York, NY, USA: ACM. 592-599.

Gordon, E. (2003) A Music Learning Theory for Newborn and Young Children. Chicago: GIA Publications.

Guha, M.L., Druin, A., Chipman, G., Fails, J.A., Simms, S., Farber, A. (2005) Working with Young Children As Technology Design Partners. Communications of the ACM, 48 (1), 39-42.

Guha, M.L., Druin, A., Chipman, G., Fails, J.A., Simms, S., Farber, A. (2004) Mixing Ideas: A New Technique for Working with Young Children As Design Partners. In: Proceedings of the 2004 Conference on Interaction Design and Children: Building a Community, IDC '04. Maryland, June 1-3 2004. New York, NY, USA: ACM. 35-42.

Hein, E. (2014) Music games in education. In: Schrier, K. (Ed.). Learning, Education and Games. Pittsburgh, PA, USA: ETC Press. 93108.

livari, N., Kinnula, M. (2016) Inclusive or Inflexible: A Critical Analysis of the School Context in Supporting Children's Genuine Participation. In: Proceedings of the 9th Nordic Conference on Human-Computer Interaction, NordiCHI '16. Gothenburg, Sweden, 23-27 October 2016. New York, NY, USA: ACM. 63:1-63:10.

livari, N., Kinnula, M., Kuure, L. (2015) With best intentions: A Foucauldian examination on 
children's genuine participation in ICT design. Behaviour \& Information Technology, 28 (2). 246-280.

Jaques-Dalcroze, Emile (1921) Rhythm, Music and Education. New York City: G. P. Putnam's Sons.

Kelly, S.R., Mazzone, E., Horton, M., Read, J.C., (2006) Bluebells: A Design Method for Childcentred Product Development. In: Proceedings of the 4th Nordic Conference on HumanComputer Interaction: Changing Roles, NordiCHI '06. Oslo, Norway, 14-18 October 2006. New York, NY, USA: ACM. 361-368.

Kokotsaki, D., Hallam, S. (2007) Higher education music students' perceptions of the benefits of participative music making. Music Education Research, 9 (1). 93-109.

Landoni, M., Rubegni, E., Nicol, E., Read, J. (2016) How Many Roles Can Children Play? In: Proceedings of the The 15th International Conference on Interaction Design and Children, IDC '16. Manchester, United Kingdom, 21-24 June 2016. New York, NY, USA: ACM. 720-725.

Large, A., Nesset, V., Beheshti, J., Bowler, L., (2006) "Bonded design": A novel approach to intergenerational information technology design. Libr. Inf. Sci. Res. 28, 64-82.

Lee, E., Nakra, T.M., Borchers, J. (2004) You're the Conductor: A Realistic Interactive Conducting System for Children. In: Proceedings of the 2004 Conference on New Interfaces for Musical Expression, NIME '04. Hamamatsu, Shizuoka, Japan, 3-5 June 2004, Singapore: National University of Singapore. 68-73.

Mansor, E.I., De Angeli, A., De Bruijn, O. (2008) Little fingers on the tabletop: A usability evaluation in the kindergarten. In: 3rd IEEE International Workshop on Horizontal Interactive Human Computer Systems. Amsterdam, Netherlands, 1-3 October 2008. IEEE. 93-96.

Mansor, E.I., De Angeli, A. De Bruijn, O. (2009) The fantasy table. In: Proceedings of the 8th International Conference on Interaction Design and Children. Milano, Como, Italy, 3-5 June 2009. New York, NY, USA: ACM. 70-79.

Markopoulos, P., Bekker, M. (2003) Interaction design and children. Interacting with Computers. 15 (2). 141-149.

Masu, R., Conci, A., Core, C., De Angeli, A., Morreale, F. (2017) Robinflock: a polyphonic algorithmic composer for interactive scenarios with children. To appear in: $14^{\text {th }}$ Sound and Music Computing Conference. Espoo, Finland, 5-8 July 2017.

Molin-Juustila, T., Kinnula, M., livari, N., Kuure, L., Halkola, E. (2015) Multiple voices in ICT design with children - a nexus analytical enquiry. Behaviour \& Information Technology, 34 (11). 1079-1091.

Morreale, F., De Angeli, A., Masu, R., Rota, P., Conci, N. (2014) Collaborative creativity: The Music Room. Personal and Ubiquitous Computing, 18 (5). 1187-1199.

Morreale, F., De Angeli, A. (2016) Collaborating with an Autonomous Agent to Generate Affective Music. Computers in Entertainment (CIE), 14 (3), 5.

Morreale, F., Masu, R., De Angeli, A. (2013) Robin: an algorithmic composer for interactive scenarios. In: Sound and Music Computing Conference. Stockholm, Sweden, 30 July - 3 August 2013. Berlin: Logos Verlag. 207-212.

Nicol, E., Hornecker, E. (2012) Using Children's Drawings to Elicit Feedback on Interactive Museum Prototypes. In: Proceedings of the 11th International Conference on Interaction Design and Children, IDC '12. Bremen, Germany, 12-15 June 2012. New York, NY, USA: ACM. 276-279.

Nijs, L., Leman, M. (2014) Interactive technologies in the instrumental music classroom: A longitudinal study with the Music Paint Machine. Computers \& Education, 73. 40-59.

Nijs, L., Moens, B., Lesaffre, M., Leman, M. (2012) The Music Paint Machine: Stimulating Selfmonitoring Through the Generation of Creative Visual Output Using a Technology-enhanced Learning Tool. Journal of New Music Research, 41 (1). 79-101.

Pachet, F. (2003) The continuator: Musical interaction with style. Journal of New Music Research, 32 (3). 333-341.

Piaget, J. (1951) Play, dreams and imitation in childhood. New York: Norton.

Piston, W. (1948) Harmony. New York: Norton.

Rajan, R.S. (2014) Tapping into Technology, Experiencing Music in a Child's Digital World. General Music Today, 28 (1), 8-11.

Read, J., Gregory, Peggy, MacFarlane, S., McManus, B., Gray, Peter, Patel, Raj (2002) An investigation of participatory design with children-informant, balanced and facilitated design. In: Proceedings of Interaction Design and Children International Workshop. Shaker Publishing.

Rodríguez-Quiles y García, J.A., Dogani, K. (2011) Music in schools across Europe: analysis, interpretation and guidelines for music education in the framework of the European Union. In: Airi, L., Marit, M. (Eds.), Music inside and Outside the School. Frankfurt am Main. 95-122. 
Saarikallio, S. (2009) Emotional self-regulation through music in 3-8-year-old children. In: ESCOM Proceedings of the 7th Triennial Conference of European Society for the Cognitive Sciences of Music. Jyväskylä, Finland, 12-16 August 2009.

Schoenberg, A. (1978) Theory of harmony. University of California Press.

Schon, D.A., DeSanctis, V. (1986) The Reflective Practitioner: How Professionals Think in Action. The Journal of Continuing Higher Education, 34 (3). 29-30.

Sims, W.L. (1986) The effect of high versus low teacher affect and passive versus active student activity during music listening on preschool children's attention, piece preference, time spent listening, and piece recognition. Journal of Research in Music Education, 34 (3). 173-191.

Sylla, C., Branco, P., Coutinho, C., Coquet, E., (2011) TUls vs. GUls: comparing the learning potential with preschoolers. Personal and Ubiquitous Computing, 16 (4). 421-432.
Taruskin, R. (2009) Music in the Nineteenth Century: The Oxford History of Western Music. Oxford University Press.

Thresher, J.M. (1964) The Contributions of Carl Orff to Elementary Music Education. Music Educators Journal, 50 (3), 43-48.

Walsh, G., Foss, E., Yip, J., Druin, A. (2013) FACIT PD: A Framework for Analysis and Creation of Intergenerational Techniques for Participatory Design. In: Proceedings of the SIGCHI Conference on Human Factors in Computing Systems, CHI '13. Paris, France, April 27 - May 02, 2013. New York, NY, USA: ACM. 28932902.

Xu, D., Read, J.C., Sim, G., McManus, B. (2009) Experience It, Draw It, Rate It: Capture Children's Experiences with Their Drawings. In: Proceedings of the 8th International Conference on Interaction Design and Children, IDC '09. Como, Italy, 3-5 June 2009. New York, NY, USA: ACM. 266-270. 